\title{
EFFICIENCY ESTIMATION OF INDUCTION MOTORS AT DIFFERENT SIZES WITH ARTIFICIAL NEURAL NETWORKS AND LINEAR ESTIMATION USING CATALOG VALUES
}

\author{
Mine SERTSÖZ ${ }^{1, *}$, Mehmet FİDAN ${ }^{1}$, Mehmet KURBAN ${ }^{2}$ \\ ${ }^{1}$ Vocational School of Transportation, Anadolu University, Eskişehir, Turkey \\ 2 Department of Electrical\&Electronics Engineering, Bilecik Şeyh Edebali University, Bilecik, Turkey
}

\begin{abstract}
Induction motors are the most preferred engines in industry because of their simple but robust structure. The efficiency of the preferred motor is crucial for the limitations of the loads to be pulled by the locomotive and the locomotive's suitability for the geographic conditions. For this reason, determining the energy efficiency and operating conditions of induction motors is crucial. It is often not possible to realize the efficiency of induction motors experimentally because it is necessary for the motor to be stopped during the experiment. This prevents the analysis of the efffects of the experiment on the energy efficiency of the motor.

The efficiency estimation of induction motors provides a significant contribution to operation and energy efficiency. There is a variety of studies in literature related to efficiency estimation. However, the future of this study is the realization of efficiency estimations of induction motors at 17 different power types with artificial neural networks and linear estimation by looking at the speed values, current and moment, listed in the manufacture's catalog in full load. Before obtaining the estimations, the statistical analysis of the correlations between efficiency and moment, efficiency and speed, efficiency and current of the motor were applied.
\end{abstract}

Keywords: Efficiency estimation, Neural networks, Linear estimation, Induction motors

\section{INTRODUCTION}

Induction motors can be designed for specific torque, rotation speed and drawn current parameters according to their use. Therefore, these different designs result in different efficiency percentages on the output of the motors. When the power of the motor is increased, the efficiency of the motor should also be increased, in order to avoid an undesired amount of lost power. However, how can we be sure that we reach the desired efficiency percentage without complex and time-consuming power measurements and calculations? Observations show that there are strong correlations between efficiency and three critical parameters of the motor: drawn current, moment and rotation speed.

In Section 2, a literature review is given about efficiency estimation in induction motors. There are six methods for efficiency estimation of induction machines.

In Section 3, information is given about the company named Gamak. The 17 induction motors' values which are used in this study are given in Table 1 from Gamak's catalog.

In Section 4, an efficiency estimation is performed with linear estimation for 17 induction motors. Firstly, the Linear Prediction (LP) model is introduced. Correlations of efficiency of motor with drawn current, output moment and rotation speed are given. The pearson correlation coefficient between efficiency and moment, efficiency and drawn current and efficiency and rotation speed; various data for the different sizes of induction motors are obtained. Lastly, the linear estimation model is created using these correlations. According to this model, estimation values are given in Table 3.

In Section 5, an efficiency estimation is performed with Artificial Neural Networks (ANN) for 17 induction motors. Firstly, the ANN model is introduced, the specifications for this are given in Figure

*Corresponding Author: msertsoz@anadolu.edu.tr

Receiving Date: 07 August 2017 Publishing Date: 29 June 2018 
1. The results of the simulation are given in Figure 2. According to this model, estimation values are given in Table 4.

In Section 6, the comparative efficiency results of the two methods, according to different input values, are given in Table 5. Root Mean Square Error (RMSE) Values are given in Table 6.

In Section 7, Tables 5 and 6 are interpreted and a decision is made about which model is more accurate.

\section{LITERATURE REVIEW}

The efficiency measurement of electric motors can be made in two ways, directly and indirectly. These methods can be called "experimental methods." IEEE 112-B and CSA-390 are direct methods and the following equation can be used:

Efficiency $\%=\frac{\text { Mechanical Output Power }}{\text { Electrical Input Power }} \times 100$

For this reason, it is necessary to measure both the mechanical output power and the electrical input power. Electrical input power can be measured accurately with the simple installation of medium-priced equipment. The mechanical output power can be defined by multiplication torque by angular velocity. While it is possible to get accurate results with a relatively simple procedure ( $\pm 1 \mathrm{RPM})$, which requires inexpensive hardware for speed measurement. But it requires a more detailed setup and more expensive equipment to get accurate results in torque measurement.

IEC 34-2 and JEC 37 are indirect methods. To avoid the complexity and cost of torque measurements, the motor's efficiency can be indirectly determined by the following equation:

Efficiency $\%=\frac{\text { Electrical Input Power-Losses }}{\text { Electrical Input Power }} \times 100$

This calculation requires the measurement of motor losses. Many motor losses, (copper, iron, mechanical), can be measured quite accurately. But the remaining losses, (leakage losses), are not measurable.

Numerous methods are proposed in literature for in situ efficiency estimation of induction machines. These methods are as follows:

1) slip method;

2) current method;

3) simplified equivalent circuit method [1];

4) simplified loss segregation method [2];

5) nonintrusive air-gap torque (AGT) (NAGT) method [3];

6) optimization-based methods [4]-[14].

Based on the National Electrical Manufacturers Association (NEMA) MG1 standard, induction motors can operate with up to $5 \%$ unbalanced voltages [15]. Also, up to $\pm 10 \%$ over/under voltage supply conditions are commonly seen in industrial facilities.

In real industrial conditions and, specifically, in weak power systems, the voltage unbalanced factor (VUF) or the over/under voltage rate can be even more severe. An unbalanced power supply occurring with a combination of over/under voltage conditions can significantly affect the machine's efficiency [15], [16]. Thus, a method which is compatible with these conditions should be employed to have a reliable estimation of the efficiency under real industrial situations.

Only the last two methods are applicable in real industrial conditions where some level of unbalanced and over/under voltage conditions exist. Unbalanced supplies can be present due to many reasons, such as 
incomplete transposition of transmission lines, open delta transformers, blown fuses on three-phase capacitor banks, unequal distribution of single-phase loads, or defective transformers in power systems [15], [16].

In the NAGT method [3], the AGT is calculated based on the voltage and current signals as well as the magnitude of the stator's resistance at the operating temperature. In this method, the effect of the unbalanced voltages is considered on the net produced torque. However, the accuracy of this method is impaired due to the fixed assumption of the no-load losses as well as stray load loss at different loading and supply voltage conditions.

Optimization-based methods are another alternatives for the efficiency estimation under real industrial conditions. In these methods, the machine's efficiency is calculated based on the estimation of parameters for the equivalent circuit in the machine with the help of an optimization-based search algorithm, (such as genetic algorithm, bacterial foraging algorithm, and multiobjective optimization).

Some studies present the optimization-based techniques for efficiency estimation under balanced supply conditions. In some, the equivalent circuit method is combined with the Genetic Algorithm (GA) to deal with the efficiency estimation problem under unbalanced supply conditions. In [7], the authors of this paper reported a new evolutionary-based (EVB) efficiency estimation algorithm which works with balanced and unbalanced supplies.

\section{GAMAK MOTORS}

The company Gamak was founded in 1961 and it is the domestic product of "Electric Motor" which is one of the most important products that Turkish industry needs for production. In a short period, Gamak started production of the first electric motor to be produced in Turkey. Gamak contributed to national production with cheaper spare parts instead of the cost of using expensively imported engines.

Gamak is one of the most important producers of electric motors in the world, not just in Turkey. With electric motors produced in the power range of $0,06 \mathrm{~kW}$ to $1000 \mathrm{~kW}$, it can meet almost all the engine needs of industry. Gamak can almost provide all the parts required for electric motor production at its own facility, and collect the entire production under one roof. The company has one of the most distinguished laboratories in Europe.

In this study, 17 different asynchronous power motors using the full load efficiency values given in Gamak's catalog are estimated with LP and ANN using nominal speed, current and torque values.

Table 1. Induction Motor Parameters for Different Sizes (4 poles, 1500 rpm, 3 phases and $400 \mathrm{~V}$ ) as listed in Gamak's catalog [17]

\begin{tabular}{|l|l|l|l|l|}
\hline Motor kW & $\begin{array}{l}\text { Speed } \\
\text { (RPM) }\end{array}$ & $\begin{array}{l}\text { Current } \\
\text { Ampere) }\end{array}$ & $\begin{array}{l}\text { Moment } \\
(\mathbf{N m})\end{array}$ & $\begin{array}{l}\text { Full Load } \\
\text { Efficiency (\%) }\end{array}$ \\
\hline 5,50 & 1465 & 11,2 & 35,9 & 87.9 \\
\hline 7,5 & 1465 & 15,4 & 48,9 & 89 \\
\hline 11 & 1465 & 21,3 & 71,7 & 90 \\
\hline 15 & 1465 & 29,4 & 97,8 & 90.6 \\
\hline 18,5 & 1470 & 34,5 & 120 & 91.3 \\
\hline 22 & 1470 & 42,5 & 143 & 91.7 \\
\hline 30 & 1470 & 55 & 195 & 92.5 \\
\hline 37 & 1470 & 67 & 240 & 92.7 \\
\hline 45 & 1470 & 80 & 292 & 93.3 \\
\hline 55 & 1475 & 96 & 356 & 93.7 \\
\hline 75 & 1480 & 133 & 484 & 94 \\
\hline 90 & 1480 & 158 & 581 & 94.3 \\
\hline 110 & 1485 & 195 & 707 & 94.5 \\
\hline 132 & 1485 & 230 & 849 & 94.7 \\
\hline 160 & 1485 & 280 & 1029 & 94.9 \\
\hline 185 & 1485 & 323 & 1190 & 94.9 \\
\hline 200 & 1485 & 350 & 1286 & 95 \\
\hline
\end{tabular}




\section{EFFICIENCY ESTIMATION WITH LINEAR ESTIMATION}

\subsection{Correlations of Efficiency of Motor with Drawn Current, Output Moment and Rotation Speed}

The main parameter which gives a numerical magnitude for the correlation of two phenomena would be covariance [18], if these phenomena are thought as random variables as shown in (3).

$\operatorname{Cov}(X, Y)=E[X Y]-E[X] E[Y]$

In (3), $E[\cdot]$ denotes the expected or mean value of the phenomenon. In discrete variables, covariance can be calculated by (4) from the samples measured for these two variables.

$\operatorname{Cov}(X, Y)=\frac{1}{n^{2}} \sum_{i=1}^{n} \sum_{j=1}^{n}\left(x_{i}-E[X]\right)\left(y_{j}-E[Y]\right)$

According to Eq-4, some idea can be obtained from the relation of events $X$ and $Y$. However, this covariance value is dependent on the magnitude of the standard deviations of $X$ and $Y$. This dependency prevents the determination of the value. To discard the effects of the standard deviations of $X$ and $Y$ and to normalize the value between 1 and -1 , the covariance value should be divided by the standard deviations of $X$ and $Y$. According to this division, the Pearson Correlation Coefficient [19] is obtained as (5).

$$
\rho(X, Y)=\frac{\operatorname{Cov}(X, Y)}{\sigma_{X} \sigma_{Y}}
$$

For obtaining the Pearson Correlation Coefficient between efficiency and moment, efficiency and drawn current and efficiency and rotation speed, various data for the various sizes of induction motors are needed. For this purpose, the parameters listed in GAMAK's catalog, which are given in Table 1 of Section 3 , is used.

If (5) is applied on Eq-3, the Pearson Correlation Coefficients are found as shown in Table-2.

Table 2. Pearson Correlation Coefficients

\begin{tabular}{ccc}
\hline $\boldsymbol{\rho}(\boldsymbol{E}, \boldsymbol{S})$ & $\boldsymbol{\rho}(\boldsymbol{E}, \boldsymbol{C})$ & $\boldsymbol{\rho}(\boldsymbol{E}, \boldsymbol{M})$ \\
\hline 0.8993 & 0.8234 & 0.8241 \\
\hline
\end{tabular}

Note: E, S, C, M denotes Efficiency, Speed, Current and Moment respectively.

According to Table 2, it can be said that the most correlated parameter with efficiency is rotation speed and the parameter least correlated with efficiency is drawn current. However, both parameters have strong correlations with efficiency, which provides the opportunity to construct a linear predictor for efficiency.

\subsection{Linear Estimation Model}

Assuming that $\widehat{E}_{\mathrm{I}}$ is the estimation value of efficiency. Then there are four linear predictors proposed as (6), (7), (8) and (9) respectively.

$$
\begin{aligned}
& \widehat{E_{\mathrm{i}, \text { all }}}=a_{M} M_{i, N \text { orm }}+a_{C} C_{i, N o r m}+a_{S} S_{i, N o r m}+\min (E) \\
& \widehat{E_{\mathrm{I}, M C}}=b_{M} M_{i, N o r m}+b_{C} C_{i, N o r m}+\min (E)
\end{aligned}
$$


$\widehat{E_{\mathrm{i}, C S}}=c_{C} C_{i, N o r m}+c_{S} S_{i, N o r m}+\min (E)$

$\widehat{E_{\mathrm{I}, M S}}=d_{M} M_{i, N o r m}+d_{S} C_{i, N o r m}+\min (E)$

For a successive estimation, input parameters of the predictors were normalized as in (10)

$X_{i, N \text { orm }}=\frac{X_{i}-\min (X)}{\max \left(X_{i}-\min (X)\right)}$

The coefficients of the predictor $\widehat{E_{\mathrm{i}, \text { all }}}$ was calculated by the correlation matrix as in (11).

$$
\begin{aligned}
& {\left[\begin{array}{l}
a_{M} \\
a_{C} \\
a_{S}
\end{array}\right]=K \cdot\left[\begin{array}{lll}
\rho(E, E) & \rho(E, M) & \rho(E, C) \\
\rho(E, M) & \rho(E, E) & \rho(E, S) \\
\rho(E, C) & \rho(E, S) & \rho(E, E)
\end{array}\right]^{-1} \cdot\left[\begin{array}{c}
\rho(E, M) \\
\rho(E, C) \\
\rho(E, S)
\end{array}\right]} \\
& K=\max \left(E_{i}-\min (E)\right)
\end{aligned}
$$

The coefficients of the predictor $\widehat{E_{\mathrm{I}, M C}}$ was calculated by the correlation matrix as in (12).

$$
\begin{gathered}
{\left[\begin{array}{l}
b_{M} \\
b_{C}
\end{array}\right]=K \cdot\left[\begin{array}{ll}
\rho(E, E) & \rho(E, M) \\
\rho(E, C) & \rho(E, E)
\end{array}\right]^{-1} \cdot\left[\begin{array}{l}
\rho(E, M) \\
\rho(E, C)
\end{array}\right]} \\
K=\max \left(E_{i}-\min (E)\right)
\end{gathered}
$$

The coefficients of the predictor $\widehat{E_{\mathrm{i}, C S}}$ was calculated by the correlation matrix as in (13).

$$
\begin{gathered}
{\left[\begin{array}{l}
C_{C} \\
C_{S}
\end{array}\right]=K \cdot\left[\begin{array}{ll}
\rho(E, E) & \rho(E, C) \\
\rho(E, S) & \rho(E, E)
\end{array}\right]^{-1} \cdot\left[\begin{array}{l}
\rho(E, C) \\
\rho(E, S)
\end{array}\right]} \\
K=\max \left(E_{i}-\min (E)\right)
\end{gathered}
$$

The coefficients of the predictor $\widehat{E_{\mathrm{I}, M S}}$ is calculated by the correlation matrix as in (14).

$$
\begin{gathered}
{\left[\begin{array}{l}
d_{M} \\
d_{S}
\end{array}\right]=K \cdot\left[\begin{array}{ll}
\rho(E, E) & \rho(E, M) \\
\rho(E, S) & \rho(E, E)
\end{array}\right]^{-1} \cdot\left[\begin{array}{l}
\rho(E, M) \\
\rho(E, S)
\end{array}\right]} \\
K=\max \left(E_{i}-\min (E)\right)
\end{gathered}
$$

For Table 1, the predictor equations are found as in (15), (16), (17) and (18) respectively.

$$
\begin{aligned}
& \widehat{E_{\mathrm{i}, \text { all }}}=1.92 M_{i, \mathrm{Norm}}-0.30 C_{i, \mathrm{Norm}}+5.07 S_{i, \mathrm{Norm}}+87.9 \\
& \widehat{E_{\mathrm{i}, M C}}=3.21 M_{i, N o r m}+3.20 C_{i, N o r m}+87.9 \\
& \widehat{E_{\mathrm{I}, C S}}=2.27 C_{i, N o r m}+4.35 S_{i, N o r m}+87.9 \\
& \widehat{E_{\mathrm{I}, M S}}=2.28 M_{i, N o r m}+4.34 C_{i, N o r m}+87.9
\end{aligned}
$$

$\widehat{E_{\mathrm{I}, C S}}$ and $\widehat{E_{\mathrm{I}, M S}}$ have close coefficients because the normalized current data and normalized moment data are so close to each other because of linear dependency.

According to the predictor equations, the predicted current values are found as in Table 3. 
Table 3. Estimation Values of Proposed Predictors

\begin{tabular}{lllll}
\hline $\begin{array}{l}\text { Full Load } \\
\text { Efficiency }\end{array}$ & $\widetilde{\boldsymbol{E}_{\mathrm{i}, \boldsymbol{a l l}}}$ & $\widetilde{\boldsymbol{E}_{\mathrm{i}, \boldsymbol{M C}}}$ & $\widetilde{\boldsymbol{E}_{\mathrm{i}, \boldsymbol{C S}}}$ & $\widetilde{\boldsymbol{E}_{\mathrm{i}, \boldsymbol{M S}}}$ \\
\hline 87.9 & 87.9 & 87.9 & 87.9 & 87.9 \\
89 & 87.916 & 87.973 & 87.928 & 87.924 \\
90 & 87.946 & 88.087 & 87.968 & 87.865 \\
90.6 & 87.979 & 88.231 & 88.022 & 88.013 \\
91.3 & 89.277 & 88.336 & 89.142 & 89.138 \\
91.7 & 89.305 & 88.471 & 89.196 & 89.180 \\
92.5 & 89.374 & 88.723 & 89.280 & 89.274 \\
92.7 & 89.432 & 88.952 & 89.360 & 89.356 \\
93.3 & 89.5 & 89.208 & 89.447 & 89.451 \\
93.7 & 90.853 & 89.524 & 90.640 & 90.652 \\
94 & 92.285 & 90.202 & 91.974 & 91.970 \\
94.3 & 93.412 & 90.688 & 92.142 & 92.146 \\
94.5 & 93.841 & 91.361 & 93.476 & 93.461 \\
94.7 & 94.028 & 92.057 & 93.710 & 93.719 \\
94.9 & 94.261 & 92.992 & 94.045 & 94.047 \\
94.9 & 94.471 & 93.812 & 94.333 & 94.340 \\
95 & 94.595 & 94.314 & 94.514 & 94.514 \\
\hline
\end{tabular}

\section{EFFICIENCY ESTIMATION WITH ARTIFICIAL NEURAL NETWORK (ANN)}

Artificial neural networks (ANN), created by imitating human brain function, can perform a process of learning through experimentation just as the human brain does. Perhaps the most important place where ANN is being used is in estimation. ANN intends to reveal the relationships between data which is sometimes easy to understand but sometimes nonlinear.

Without any assumption, ANN can provide modeling without any additional information between input and output. Therefore, ANN can easily provide nonlinear modeling [20]. Network training is provided by input and output information according to these inputs.

Back Propagation Networks (BPN), also used in this study, is a network structure that is frequently used. The standard back propagation algorithm is a gradient descent algorithm in which the net weights advance in the negative gradient of the performance function. Many types of back propagation algorithms are based on standard optimization techniques such as gradient descent and the Newton method. [20] The backpropagation algorithmwas first proposed by Werbos [21] and later by Rumelhart [22], independently of each other. In 1986, Rumelhart and his colleagues rediscovered the backpropagation algorithm, making the algorithm known and widely used.

In many previous studies it has been shown that artificial neural networks (ANN) give better results than conventional methods of estimation, [23-25]. The reason for the use of ANN is its success, especially for nonlinear input data. [26] And the Back Propagation Networks (BPN), which is a type of ANN and also used in this study, is the most commonly used learning algorithm.

In this study, the values of speed, current and torque, which are given in Table 1, are used. In the first experiment, all of these three parameters were applied as the input vector of the NN. In the following three experiments, each parameter is applied as a single input value. At this stage, inputs are normalized first. A forward feed back propagation network is used, as can be seen in Figure 1. The remarkable point is Mean Square Error (MSE) as a performance function, 1 as the number of layers and 30 as the number of neurons. There is no hidden layer because hidden layers cause the exponent of the equation. In this study there is a logistic regression need for to compare with LP.Later, the network is trained to make estimations. The results can be seen in Figure 2 and Tablo 4. 
Sertsöz et al. / Anadolu Univ. J. of Sci. and Technology A-Appl. Sci. and Eng. 19 (2) - 2018

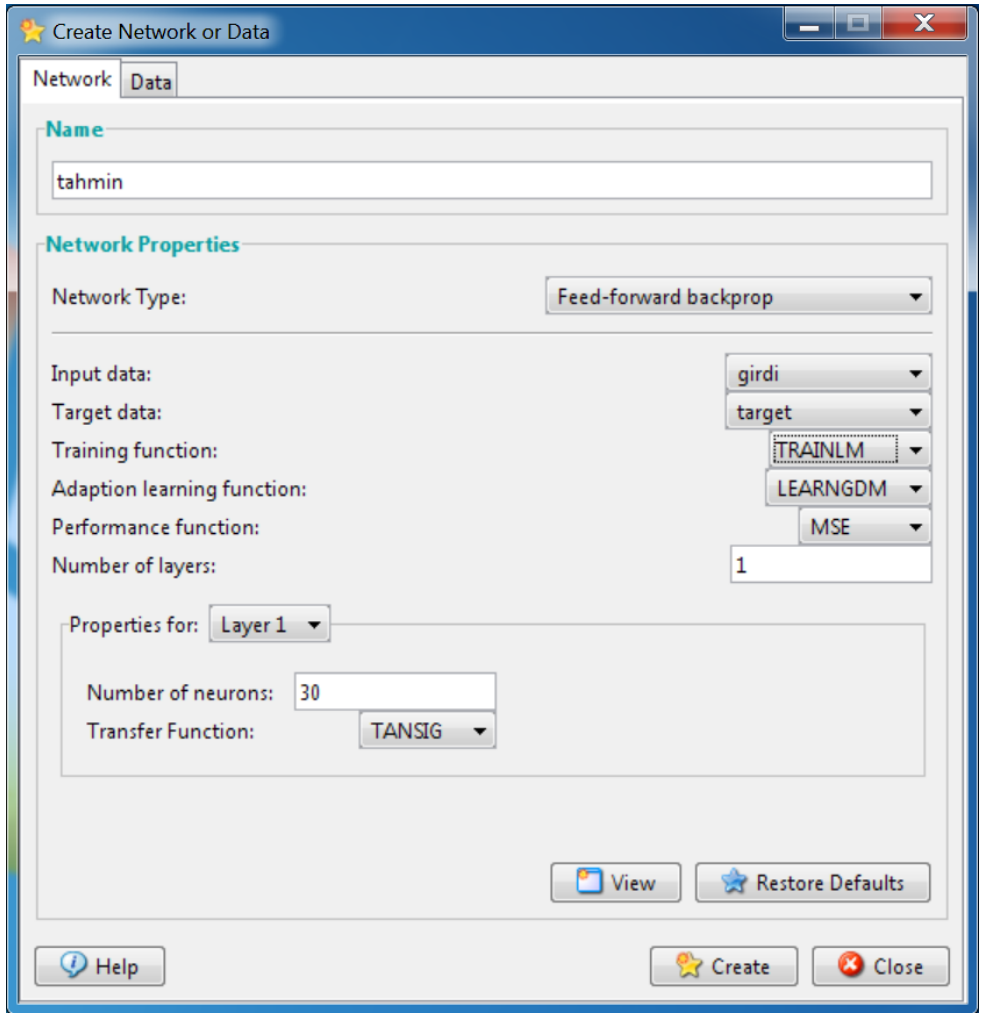

Figure 1. Specifications of the Network

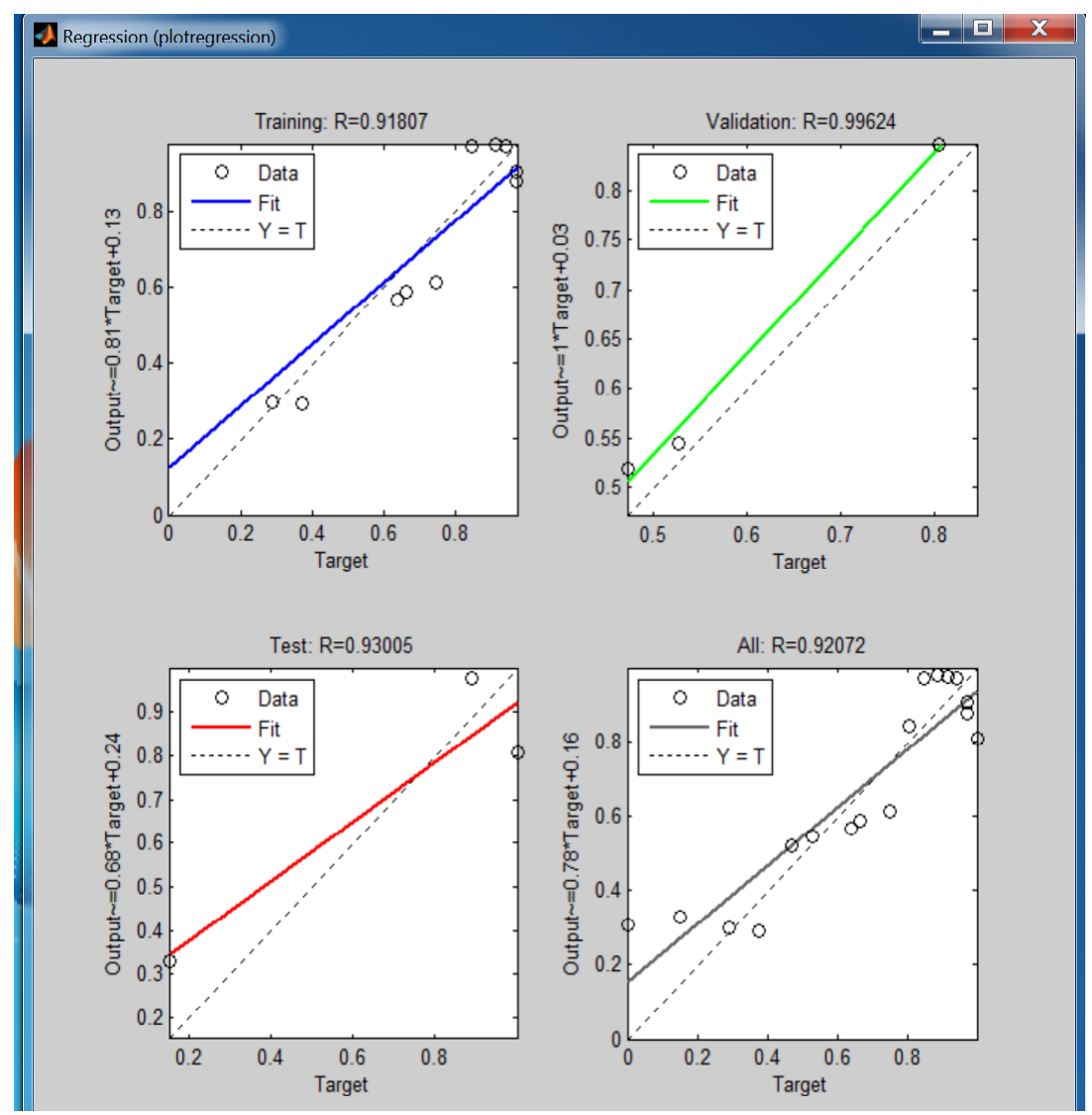

Figure 2. Simulations Results (According to three inputs) 
Sertsöz et al. / Anadolu Univ. J. of Sci. and Technology A-Appl. Sci. and Eng. 19 (2) - 2018

Table 4. Estimation Values of ANN

$\begin{array}{lllll}\begin{array}{l}\text { Motor } \\ \text { kW }\end{array} & \begin{array}{l}\text { Efficiency Estim. } \\ \text { (\%) }\end{array} & \begin{array}{l}\text { Efficiency } \\ \text { Estim. }(\%)\end{array} & \begin{array}{l}\text { Efficiency } \\ \text { Estim. }(\%)\end{array} & \begin{array}{l}\text { Efficiency Estim. } \\ \text { (\%) }) \\ \text { (speed, current }\end{array} \\ & \begin{array}{l}\text { (momeent) } \\ \text { (md moment) }\end{array} & & & \\ 5,5 & 88,869 & 89,508 & 88,16 & 88,287 \\ 7,5 & 89,130 & 89,508 & 88,273 & 88,336 \\ 11 & 89,601 & 89,508 & 88,722 & 88,489 \\ 15 & 90,426 & 89,508 & 91,060 & 90,534 \\ 18,5 & 91,732 & 91,945 & 91,995 & 91,324 \\ 22 & 92,034 & 91,945 & 92,802 & 91,521 \\ 30 & 92,364 & 91,945 & 92,980 & 94,288 \\ 37 & 92,863 & 91,945 & 93,440 & 93,056 \\ 45 & 93,293 & 91,945 & 92,773 & 93,115 \\ 55 & 92,757 & 93,699 & 94,568 & 93,712 \\ 75 & 94,021 & 93,979 & 93,918 & 94,812 \\ 90 & 94,751 & 93,979 & 94,240 & 94,302 \\ 110 & 94,402 & 94,810 & 94,483 & 94,514 \\ 132 & 94,834 & 94,810 & 94,458 & 94,755 \\ 160 & 95,086 & 94,810 & 94,767 & 94,884 \\ 185 & 95,099 & 94,810 & 94,750 & 94,959 \\ 200 & 95,099 & 94,810 & 94,631 & 95,003\end{array}$

\section{COMPARATIVE RESULTS}

The comparative efficiency results of the two methods according to different input values are given in Table 5. Root Mean Square Error (RMSE) values are given in Table 6. One thing to note is that while $\mathrm{LP}$ requires at least two types of inputs, $\mathrm{NN}$ requires only single type of input.

Table 5. Estimation Values of LP and ANN

\begin{tabular}{|c|c|c|c|c|c|c|c|c|}
\hline $\begin{array}{l}\text { Full Load } \\
\text { Efficiency }\end{array}$ & $\begin{array}{c}\widetilde{E_{\mathrm{I}, \text { all }}} \\
\mathbf{L P} \\
\end{array}$ & $\begin{array}{c}\widetilde{E_{\mathrm{I}, M C} C} \\
\mathbf{L P} \\
\end{array}$ & $\begin{array}{c}\widetilde{E_{\mathrm{i}, C S}} \\
\mathbf{L P} \\
\end{array}$ & $\begin{array}{c}\widetilde{E_{\mathrm{i}, M S}} \\
\mathbf{L P} \\
\end{array}$ & $\begin{array}{l}\widetilde{E_{\mathrm{i}, \text { all }}} \\
\text { ANN }\end{array}$ & $\begin{array}{c}\widehat{E_{\mathrm{I}, S}} \\
\text { ANN } \\
\end{array}$ & $\begin{array}{c}\widehat{E_{\mathrm{I}, C}} \\
\text { ANN } \\
\end{array}$ & $\begin{array}{c}\widehat{E_{\mathrm{I}, \boldsymbol{M}}} \\
\text { ANN } \\
\end{array}$ \\
\hline 87.9 & 87.9 & 87.9 & 87.9 & 87.9 & 88,869 & 89,508 & 88,16 & 88,287 \\
\hline 89 & 87.916 & 87.973 & 87.928 & 87.924 & 89,13 & 89,508 & 88,273 & 88,336 \\
\hline 90 & 87.946 & 88.087 & 87.968 & 87.865 & 89,601 & 89,508 & 88,722 & 88,489 \\
\hline 90.6 & 87.979 & 88.231 & 88.022 & 88.013 & 90,426 & 89,508 & 91,06 & 90,534 \\
\hline 91.3 & 89.277 & 88.336 & 89.142 & 89.138 & 91,732 & 91,945 & 91,995 & 91,324 \\
\hline 91.7 & 89.305 & 88.471 & 89.196 & 89.180 & 92,034 & 91,945 & 92,802 & 91,521 \\
\hline 92.5 & 89.374 & 88.723 & 89.280 & 89.274 & 92,364 & 91,945 & 92,98 & 94,288 \\
\hline 92.7 & 89.432 & 88.952 & 89.360 & 89.356 & 92,863 & 91,945 & 93,44 & 93,056 \\
\hline 93.3 & 89.5 & 89.208 & 89.447 & 89.451 & 93,293 & 91,945 & 92,773 & 93,115 \\
\hline 93.7 & 90.853 & 89.524 & 90.640 & 90.652 & 92,757 & 93,699 & 94,568 & 93,712 \\
\hline 94 & 92.285 & 90.202 & 91.974 & 91.970 & 94,021 & 93,979 & 93,918 & 94,812 \\
\hline 94.3 & 93.412 & 90.688 & 92.142 & 92.146 & 94,751 & 93,979 & 94,24 & 94,302 \\
\hline 94.5 & 93.841 & 91.361 & 93.476 & 93.461 & 94,402 & 94,81 & 94,483 & 94,514 \\
\hline 94.7 & 94.028 & 92.057 & 93.710 & 93.719 & 94,834 & 94,81 & 94,458 & 94,755 \\
\hline 94.9 & 94.261 & 92.992 & 94.045 & 94.047 & 95,086 & 94,81 & 94,767 & 94,884 \\
\hline 94.9 & 94.471 & 93.812 & 94.333 & 94.340 & 95,099 & 94,81 & 94,75 & 94,959 \\
\hline 95 & 94.595 & 94.314 & 94.514 & 94.514 & 95,099 & 94,81 & 94,631 & 95,003 \\
\hline
\end{tabular}

Table 6. RMSE of Estimation Values LP and ANN

\begin{tabular}{|c|c|c|c|c|c|c|c|}
\hline \multicolumn{4}{|c|}{ Linear Estimation } & \multicolumn{4}{|c|}{ Artificial Neural Networks } \\
\hline$\overline{\bar{E}_{\mathrm{l}, \text { all }}}$ & $\widehat{\widehat{E_{\mathrm{I}, M C}}}$ & $\widetilde{E_{\mathrm{L}, C S}}$ & $\widetilde{\bar{E}_{\mathrm{L}, M S}}$ & $\widetilde{\bar{E}_{\mathrm{L}, \text { all }}}$ & $\widehat{E_{\mathrm{L}, S}}$ & $\widehat{E_{\mathrm{L}, C}}$ & $\widehat{E_{\mathrm{L}, M}}$ \\
\hline 2,076 & 2,089 & 2,178 & 2,18 & 0,311 & 0,552 & 0,534 & 0,403 \\
\hline
\end{tabular}




\section{CONCLUSION}

In this study, Artificial Neural Network (ANN) and Linear Estimation (LP) which are considered as optimization techniques were used for the efficiency estimation of 17 induction motors. Subsequently, two different methods were compared according to the efficiency values given in the manufacturer's catalog in Table 5 and 6 . According to these Tables, as expected, the combination of speed and current and torque values are the most accurate results. With these three inputs, the model performs quite well.

Also, using moment and drawn current data in a single estimation model is inappropriate because they have the same information according to linear dependency for LP. However, if the speed data is used in any predictor, the predictor gives better results because of the strong correlation with efficiency.

For ANN, another noteworthy point is that the closest value is obtained from current input excepting three inputs. The other finding is that it is not possible to use speed alone as an input in the estimation of efficiency.

To understand which model is more accurate the RMSE values can be studied. In Table 6, ANN's RMSE values are less than LP. As shown in previous studies, this research provides evidence that ANNs give better results than conventional methods of estimation.

\section{REFERENCES}

[1] Kueck JD, Olszewski M, Casada DA, Hsu J, Otaduy PJ and Tolbert LM. Assessment of Methods for Estimating Motor Efficiency, Load Under Field Conditions. Oak Ridge Nat. Lab., Oak Ridge, TN, Rep. ORNL/ TM-13165, 1996.

[2] In-plant electric motor loading and efficiency techniques, Ontario Hydro, Toronto, ON, Canada, Rep. TSDD-90-043, 1990.

[3] Lu B, Habetler TG and Harley RG. A nonintrusive and in-service motor-efficiency estimation method using air-gap torque with considerations of condition monitoring, IEEE Trans. Ind Appl vol. 44, no. 6, pp. 1666-1674, Nov./Dec. 2008.

[4] A. Charette J. Xu, Ba-Razzouk A, Pillay P. and Rajagopalan V. The use of the genetic algorithm for in situ efficiency measurement of an induction motor. In Proc. IEEE Power Eng. Soc. Winter Meet, 2000, pp. 392-397.

[5] Phumiphak P and Chat-uthai C. Nonintrusive method for estimating field efficiency of inverter-fed induction motor using measured values. In Proc IEEE Int Conf Sustainable Energy Technol, 2008, pp. 580-583.

[6] Aspalli MS Shetagar SB and Kodad SF. Estimation of induction motor field efficiency for energy audit and management using genetic algorithm. In Proc. Int. Conf. Sens Technol, 2008, pp. 440-445.

[7] Siraki A and Pillay P. An in situ efficiency estimation technique for induction machines working with unbalanced supplies. IEEE Trans Energy Convers, vol. 27, no. 1, pp. 85-95, Mar. 2012.

[8] Lu B, Wenping C, French I, Bradley KJ and Habetler, TG. Nonintrusive efficiency determination of in-service induction motors using genetic algorithm and air-gap torque methods. In Conf Rec IEEE 42nd IAS Annual Meeting, 2007, pp. 1186-1192.

[9] Phumiphak T and Chat-uthai C. Estimation of induction motor parameters based on field test coupled with genetic algorithm. In Proc Int Conf Power Syst Technol, 2002, pp. 1199-1120. 
[10] Pillay P, Levin V, Otaduy P and Kueck J. In-situ induction motor efficiency determination using the genetic algorithm. IEEE Trans. Energy Convers., vol. 13, no. 4, pp. 326-333, Dec. 1998.

[11] Phumiphak T and Chat-uthai C. An economical method for induction motor field efficiency estimation for use in on-field energy audit and management. In Proc, Int Conf Power Syst Technol, 2004; pp. 1250-1254.

[12] Gomez JR, Quispe EC. de Armas MA and Viego PR, Estimation of induction motor efficiency insitu under unbalanced voltages using genetic algorithms. In Proc, Int Conf Elect Mach, 2008, pp. $1-4$.

[13] Cunkas M and Sag T. Efficiency determination of induction motors using multi-objective evolutionary algorithms,” Adv. Eng. Software, Feb. 2010, vol. 41, no. 2, pp. 255-261.

[14] Sakthivel VP, Bhuvaneswari R and Subramanian S. Non-intrusive efficiency estimation method for energy auditing and management of inservice induction motor using bacterial foraging algorithm, IET Elect Power Appl, Sep. 2010; vol. 4, no. 8, pp. 579-590.

[15] Siddique A, Yadava GS and Singh B. Effects of voltage unbalance on induction motors. In Conf, Rec IEEE Int Symp Elect Insul, 2004; pp. 26-29.

[16] Lee CY. Effects of unbalanced voltage on the operation performance of a three-phase induction motor, IEEE Trans Energy Convers, Jun. 1999; vol. 14, no. 2, pp. 202-208.

[17] http://www.gamak.com/uploads/files/catalogue/Gamak-2016-Urun-katalogu-tr.pdf

[18] Hazewinkel Michiel, ed., Covariance, Encyclopedia of Mathematics, Springer, ISBN: 978-155608-010-4, 2001.

[19] SPSS Tutorials: Pearson Correlation, Retrieved 2017-05- 14.

[20] Hamzaçebi C, Kutay F. Yapay Sinir Ağları İle Türkiye Elektrik Enerjisi Tüketiminin 2010 Yılına Kadar Tahmini. Gazi Üniv Müh Mim Fak Der J Fac Eng Arch Gazi Univ, 2004; Cilt 19, No 3, 227 233,

[21] Werbos PJ, Beyond Regression: New Tools for Estimation and Analysis in the Behavioral Sciences, PhD thesis, Harvard University, 1974.

[22] Rumelhart DE, Hinton, GE, Williams RJ. Learning Internal Represantation by BackPropagating Errors, In: Rumelhart DE, McCleland JL, The PDP Research Group, Paralel Distributed Processing: Explorations in the Microstructure of Cognition, MIT Press, MA, 1986.

[23] Hill T, O’Connor M, Remus, W. Neural Networks Models for Time Series Forecasts, Management Sciences, Cilt 42, No 7,1082-1092, 1996.

[24] Sharda R, Patil RB. Connectionist Approach to Time Series Estimation: An Emprical Test. Journal of Intelligent Manufacturing, Cilt 3, 317-323, 1992.

[25] Tang Z, Almeida C, Fishwick PA, Time Series Forecasting Using Neural Networks vs Box-Jenkins Methodology, Simulation, 1991; Cilt 57, No 5, 303-310.

[26] Zhang G, Patuwo BE, Hu MY. Forecasting with Artificial Neural Networks: The State of the Art, Inter Journal of Forecasting, 1998; Cilt 14, 35- 62. 